\title{
An assessment of monsoon precipitation changes during 1901-2001
}

\author{
Lixia Zhang • Tianjun Zhou
}

Received: 10 December 2009/ Accepted: 8 January 2011/Published online: 20 January 2011

(C) The Author(s) 2011. This article is published with open access at Springerlink.com

\begin{abstract}
Changes of global land monsoon precipitation are assessed by using three sets of rain-gauge precipitation data for the period of 1901-2002 compiled by GPCC, CRU and Dai-dataset, respectively. The three datasets show consistent long-term changes of precipitation over the monsoon region with slightly different amplitudes. During 1901-2001, global land monsoon precipitation (GMI) exhibits multi-decadal variations, with an overall increasing trend from 1901 to 1955 , followed by a decreasing trend up to 2001. The upward trends of global and Northern hemispheric land monsoon precipitation during 1901-1955 are mainly resulted from the increased precipitation over the North African, Indian and East Asian monsoon domains. For the whole period of 1901-2001, precipitation averaged over the Northern Hemisphere and global land monsoon areas both exhibit a decreasing trend although it is only statistically significant at the $5 \%$ level for the Northern Hemisphere. The robust decreasing trend of Northern hemispheric land monsoon precipitations during the twentieth century mainly comes from the downward trend of North African and eastern part of Indian monsoon precipitation and occurs mainly after the 1950s. The first leading mode of Empirical orthogonal function (EOF) analysis of precipitation annual range features a coherent change of North African, South Asian, Northeast China,
\end{abstract}

L. Zhang $\cdot$ T. Zhou $(\bowtie)$

LASG, Institute of Atmospheric Physics,

Chinese Academy of Sciences, Beijing, China

e-mail: zhoutj@lasg.iap.ac.cn

L. Zhang

e-mail: lixiazhang@mail.iap.ac.cn

L. Zhang

Graduate University of Chinese Academy of Sciences,

Beijing, China southern South African, eastern Australian and western American monsoon, and a coherent change over the equatorial South African monsoon and eastern American monsoon. The corresponding principal component time series also indicate that the majority of global land monsoon precipitation has experienced an increasing tendency from 1901 to 1955 and a decreasing trend since the 1950s. Examination on the impact of station number change indicates a negligible influence on the results, especially after 1905 .

Keywords Global monsoon - Long-term change · Decadal variability

\section{Introduction}

Like temperature, precipitation is an important climate variable whose long-term changes are of great interest to the society. Considerable efforts have been devoted to compiling, analyzing and assessing long-term changes in precipitation over land by using rain gauge measurements (e.g., Diaz et al. 1989; Hulme 1995; Dai et al. 1997; New et al. 2001; Trenberth et al. 2007). Estimates of long-term precipitation trends often contain large uncertainties, because of large natural variability and lack of data over many land areas and the oceans, and because of changes in station networks, rain gauge types and observational practices.

Despite these problems, precipitation changes show strong regional features. For example, for the past 100 years (1906-2005), it has become significantly wetter in eastern parts of North and South America and northern Europe, but drier in the Sahel, the Mediterranean, southern Africa and parts of southern Asia (Trenberth et al. 2007). 
There exists a strong contrast in precipitation between the tropics and high latitudes of the northern hemisphere (Hulme 1995). A long-term trend in the twentieth century land precipitation was separated from other variations by Dai et al. (1997), with increases over northern mid-high latitudes and decreases in the low-latitudes. Precipitation over East Asia was generally above normal in the 1950s and 1990s (Wang et al. 2004). Zhang et al. (2007) argued that anthropogenic forcing contributed significantly to the observed precipitation increases in the northern midlatitudes, drying in the northern subtropics and tropics.

Since monsoons define essential features of the earth's climate, and monsoon precipitation affects over two-thirds of the world's population (Wang and Ding 2008), detecting the long-term changes of monsoon precipitation and understanding the potential mechanisms are of great scientific and societal importance. Although previous analyses of land precipitation (e.g., Diaz et al. 1989; Dai et al. 1997) include all the monsoon regions, the changes of monsoon precipitation during the whole twentieth century have never been examined specifically.

The global monsoon system is a persistent global scale overturning of the atmosphere that varies according to the time of year (Trenberth et al. 2000). It is the response of the coupled climate system to the annual variation of solar forcing (Wang and Ding 2008). The dominant monsoon systems in the world include the Asian-Australian, African, and the American monsoons (Webster et al. 1998). All regional monsoons are coordinated by the annual cycle of solar radiation and connect with each other (Meehl 1997; Lau and Weng 2002; Biasutti et al. 2003; Zhang et al. 2005; Hoerling et al. 2006). Hence, it is desirable to examine the monsoon variability from a global perspective. There have been many studies focusing on the regional monsoon systems, and each monsoon system has its own specific characteristics in terms of variability (Kripalani and Kulkarni 2001; Jones et al. 2004; Schreck and Semazzi 2004; Yu et al. 2004; Yu and Zhou 2007; Zhou et al. 2009a). Using the precipitation to estimate the monsoon intensity makes it easier to compare different monsoon systems. By using four sets of rain gauge observation precipitation datasets compiled for the period of 1948-2003, Wang and Ding (2006) (hereafter WD2006) found an overall weakening of global land monsoon precipitation over the last 56 years. It is the combination of monsoon area and precipitation intensity changes that led to the overall weakening trend of global land monsoon precipitation accumulation during the last 56 years (Zhou et al. 2008a). Based on an Atmospheric General Circulation Model driven by historical sea surface temperatures covering the same period, this weakening tendency has been reasonably reproduced and the forcing mechanism comes from the tropical ocean warming in the past decades (Zhou et al. 2008b).
Previous studies on the global monsoon mainly focus on the recent half century. Detecting the potential anthropogenic climate change needs a long-time perspective. How the global monsoon precipitation has changed during the twentieth century remains unknown. Discussions on the issue were limited by the scarcity of long-term reliable dataset. Progress has been made in recent years in creating long-term precipitation datasets based on rain gauge records (Dai et al. 1997; Chen et al. 2001; Mitchell and Jones 2005; Schneider et al. 2008). The availability of these datasets has provided us opportunities to examine the changes of global land monsoon precipitation during the whole twentieth century. This is the main motivation of this study. Some specific questions to be addressed include: (1) Is there any long-term trend in global land monsoon precipitation over the twentieth century? Is the previously revealed decreasing tendency of global land monsoon precipitation over the past 56 years a phenomenon of recent half century or the whole twentieth century? (2) Does the precipitation over different monsoon regions change coherently and what is the distinctive leading mode?

The rest of the paper is organized as follows. The observational data and the analysis method are described in Sect. 2. A validation on data quality is presented in Sect. 3. The results of analysis are presented in Sect. 4. Summary and discussion are given in Sect. 5.

\section{Data and analysis method}

Two sets of monthly precipitation data for global land surface on a $0.5^{\circ}$ latitude/longitude grid are used: (1) the precipitation data developed by the Global Precipitation Climatology Centre (hereafter GPCC). The GPCC Full Data Reanalysis Version 4 for the period 1901-2002 is used (ftp://ftp-anon.dwd.de/pub/data/gpce/html/fulldata download.html) (Schneider et al. 2008); (2) the dataset constructed by the Climate Research Unit (CRU) for the period of 1901-2002 (Mitchell and Jones 2005).

Another two gridded precipitation anomaly datasets are also employed in this work. (1) Global Historical Climatology Network v2 (GHCN) provided by NOAA/National Climatic Data Center (http://www.ncdc.noaa.gov/temp-andprecip/ghen-gridded-prcp.html). It has a spatial resolution of $5^{\circ}$ latitude/longitude for the period of 1901-2002 and precipitation anomalies are relative to 1961-1990. (2) Precipitation anomaly data compiled by Dr. Aiguo Dai for the period of 1901-1995 and the resolution of the longitude-latitude grid is $2.5^{\circ} \times 2.5^{\circ}$ (http://data.giss.nasa.gov/ precip_dai/) (Dai et al. 1997). Anomalies are calculated relative to the 1951-1979 period. The dataset was based on the quality-controlled NOAA Baseline precipitation station 
data and the latest station data from NOAA NCEP, which covers the period from 1850 to 1995 . This datasets is referred to as Dai-dataset in the following discussion.

In order to estimate the magnitude of the station-coverage-induced error, the original station rainfall monthly data from the GHCN2 (ftp://ftp.ncdc.noaa.gov/pub/data/ $\mathrm{ghcn} / \mathrm{v} 2 /)$ is also used.

We employ the monsoon precipitation intensity and monsoon domain definition as WD2006. Annual range (AR), defined by the local summer-minus-winter precipitation, is used to measure monsoon precipitation intensity. Summer means June-July-August (JJA) in the Northern Hemisphere (NH) and December-January-February (DJF) in the Southern Hemisphere (SH). The monsoon precipitation domain is defined by the region in which the AR exceeds $180 \mathrm{~mm}$ and the local summer precipitation exceeds $35 \%$ of annual precipitation. This definition agrees well with the monsoon domains that have been defined by Wang and Ding (2008). The NH-averaged JJA precipitation and SH-averaged DJF precipitation falling in the monsoon domain are used to measure the strength of $\mathrm{NH}$ and $\mathrm{SH}$ summer monsoon precipitation (hereafter NHMI and SHMI, respectively). The sum of NHMI and SHMI is used to quantify the strength of global monsoon (GMI).

To reveal the coherent pattern of the change in global monsoon precipitation intensity, an empirical orthogonal function (EOF) analysis is performed on the yearly AR in global land monsoon domains. Three methods were used to test the significance of the derived trend. The first is trendto-noise ratios test (T-N test hereafter) which relies on least square regression model (Woodward and Gray 1993). The second method to quantify the direction and magnitude of the trend of raw data is based on the nonparametric Mann-Kendall (MK test hereafter) rank statistics (Kendall 1955). Unlike the linear regression method, this test is insensitive to individual outliers and to the start and end points. Alternatively, the significance of test is re-tested through 1000-ensemble Monte Carlo (MC test hereafter) simulation procedure as explained by Wilks (1995).

\section{Comparison of three datasets}

\subsection{Global and zonal mean land precipitation changes}

Previous study suggested that the regional area-means which are calculated from datasets on different grid resolutions should not be compared (Schneider et al. 2008). To reveal the consistency of the three datasets, the original datasets of GPCC, CRU and Dai-dataset were re-gridded onto the same resolutions by using distance-weighted averaging interpolation method. The target resolution is $5^{\circ}$ latitude/longitude, which is the same as GHCN dataset.
The changes of global and hemispheric land precipitation derived from Dai-dataset have been well documented by Dai et al. (1997) and the results are highly consistent with the previous studies (Bradley et al. 1987; Diaz et al. 1989; Vinnikov et al. 1990; Nicholls and Lavery 1992). By sampling the stations which has existed since 1900 and 1930, most the global and hemispheric precipitation changes of Dai-dataset were also evident in the sampled datasets. Moreover, the long-term variations of precipitation derived from Dai-dataset have a reasonable relationship with total cloud cover (Dai et al. 1997). Therefore, we employ precipitation variations derived from the Dai-dataset as reference variations.

The normalized time series of annual precipitation anomalies averaged from global land, northern hemisphere and southern hemisphere are shown in Fig. 1. The standard deviations of ensemble mean of four datasets are 15.3, 13.5 and $43.8 \mathrm{~mm}$ for the global, northern and southern hemispheric mean precipitation, respectively. The major changes in global and hemispheric mean precipitation derived from GPCC, CRU and GHCN are similar to that derived from Dai-dataset, the results are also similar to those results reported in many previous analyses (e.g., Bradley et al. 1987; Diaz et al. 1989; Vinnikov et al. 1990; Nicholls and Lavery 1992; Dai et al. 1997). The discrepancies of the anomalies among three datasets are small, and their time evolutions are consistent. The time series indicate overall upward trends in the global and northern hemispheric (hereafter $\mathrm{NH}$ ) mean land precipitation, which are significantly different from zero at the $99 \%$ confidence level in GPCC and CRU, but insignificant in GHCN and Daidataset (See Table 1). The trend is not strictly linear over the past 100 years. All datasets show an overall increasing trend from 1901 to the 1950s, a decline from the middle 1970 s to the early 1990s and then an afterward recovery in global (Fig. 1a), northern hemispheric (Fig. 1b) mean land precipitation. There is also an evident increasing trend since the 1980s in all three areas. The change of southern hemisphere (hereafter $\mathrm{SH}$ ) precipitation is small, especially for the period 1920-1970. Multi-decadal oscillations are evident among the $\mathrm{NH}, \mathrm{SH}$, and global precipitations. Particularly worthy of note is the peak in global and $\mathrm{NH}$ precipitation between 1950 and 1960, which has been documented previously by Dai et al. (1997), New et al. (2001) and it's not an artifact due to the changes of station networks. Another maximum peak stands out around 1975 in global and $\mathrm{SH}$ precipitation. The strong drought periods are seen in the 1910s and 1980-1990s.

To further confirm the consistency of three datasets in measuring the long-term change of precipitation, changes of zonal mean precipitation averaged in every 20 latitudes band from $40^{\circ} \mathrm{S}$ to $40^{\circ} \mathrm{N}$ are compared in Fig. 2. The time series derived from different datasets matches well with 
(a) Global

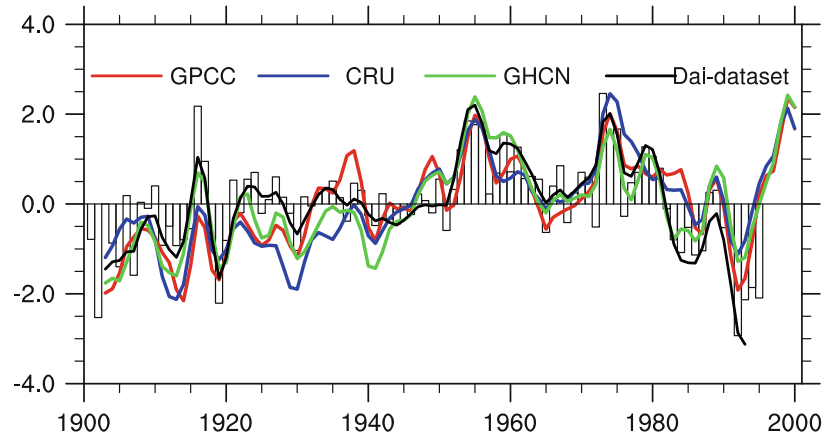

(b) $\mathrm{NH}$

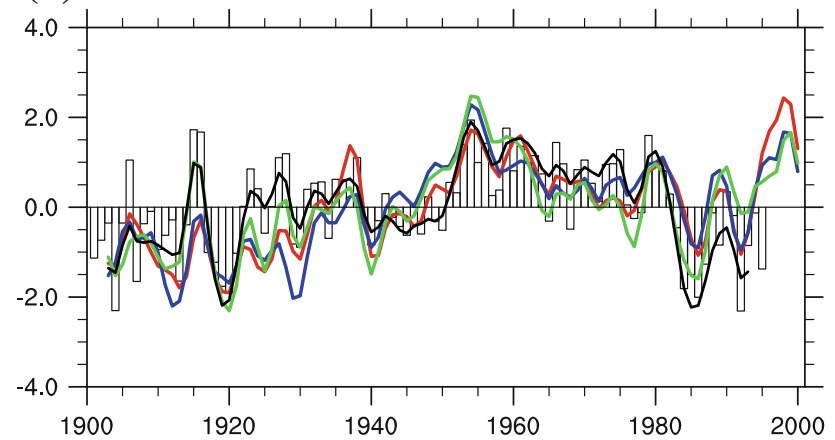

(c) $\mathrm{SH}$

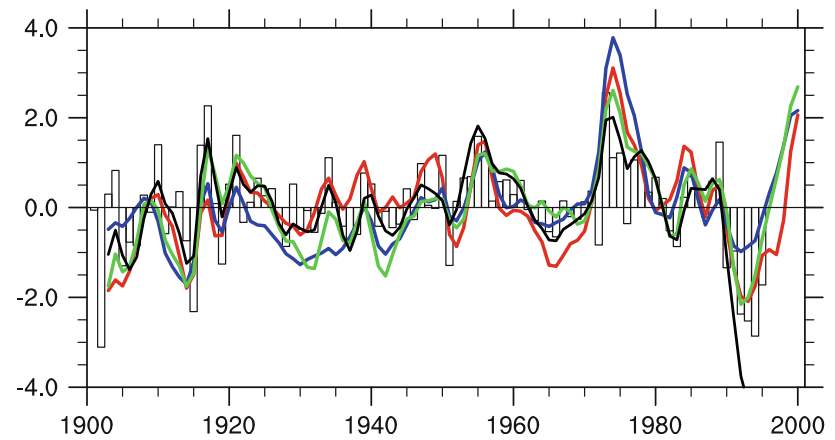

Fig. 1 Normalized time series of area averaged land annual precipitation anomalies: a global, b Northern hemisphere, c Southern hemisphere. The bars are yearly precipitation based on Dai-dataset. The anomalies are calculated relative to the climate mean of 1951-1979 for GPCC, CRU and Dai-dataset, while relative to 1961-1990 for GHCN. The red, blue, green and black lines are 5-year running mean of GPCC, CRU, GHCN and Dai-dataset, respectively

each other. The correlation coefficients among them are above 0.60 . The maximum around 1950s mainly appeared in the latitudes of $40^{\circ} \mathrm{S}-20^{\circ} \mathrm{S}, 0^{\circ}-20^{\circ} \mathrm{N}$, and $20^{\circ}-40^{\circ} \mathrm{N}$ and is evident in all datasets. The peak around the mid1970 s stands out mainly in the latitudes of $40^{\circ} \mathrm{S}-20^{\circ} \mathrm{S}$, $0^{\circ}-20^{\circ} \mathrm{S}$, and $20^{\circ}-40^{\circ} \mathrm{N}$. All datasets exhibit a drying trend from the 1970s to the 1990s. The common features shown above confirm the consistency of the datasets employed in this study.

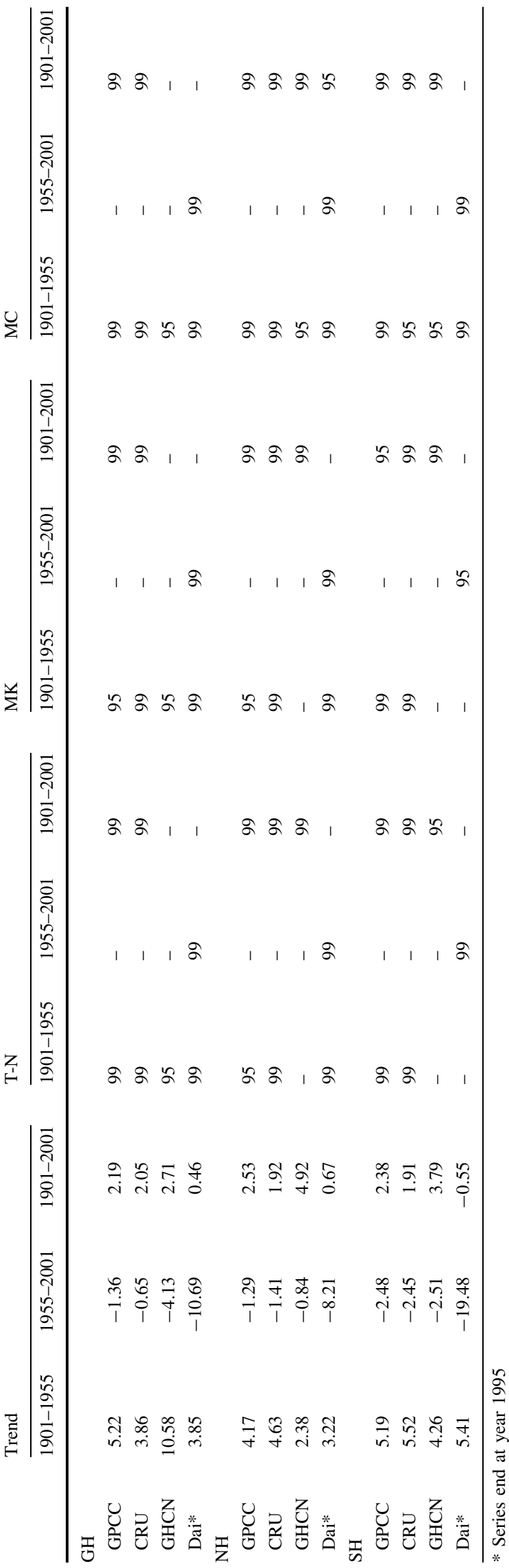




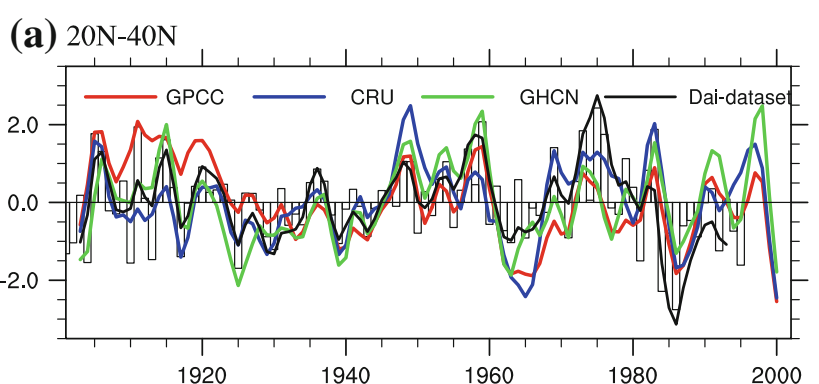

(b) $0-20 \mathrm{~N}$

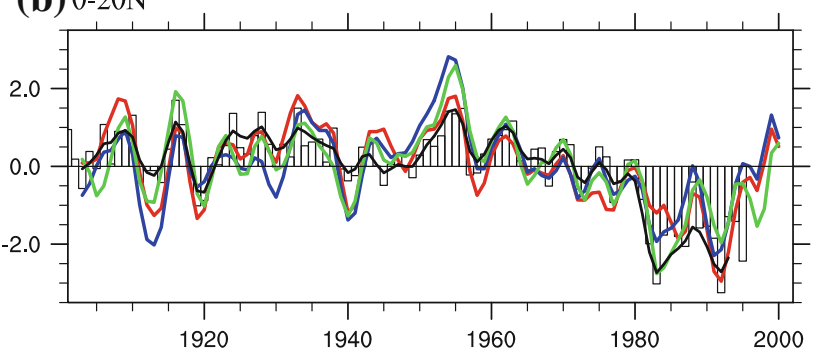

(c) $0-20 \mathrm{~S}$

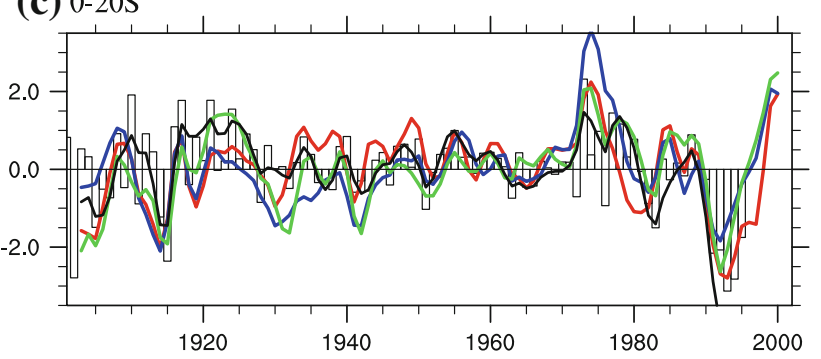

(d) $20 \mathrm{~S}-40 \mathrm{~S}$

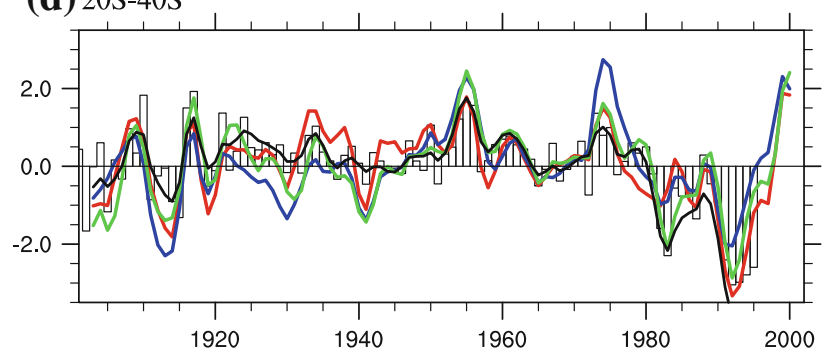

Fig. 2 Same as Fig. 1, but for the annual zonal mean precipitation in 20 latitude bands

As shown in Figs. 1, 2, the above-normal anomalies during the period of 1950-1960 are most robust during the whole 100 years. The spatial patterns of the anomalies for 1950-1960 relative to the whole 100 years (1901-1995 for Dai-dataset) are shown in Fig. 3. The four datasets generally exhibit similar patterns. The middle-high latitudes of Eurasia continent and the African continent are wetter than normal during 1950-1960. Most part of the American continent is dominated by dry anomalies. The precipitation over Australia exhibits a zonal dipole pattern with wetter anomalies in the east but drier anomalies in the west. The most significant discrepancy among the four datasets is seen over the Tibet Plateau, where no data is available in CRU, GHCN and Dai-dataset, while the Tibet Plateau undergone strong drying anomaly in GPCC. The anomaly over the Tibet Plateau revealed by GPCC data should be artifact. Note the Tibetan Plateau is out of the traditional scope of East Asian summer monsoon domain.

Since the changes of precipitation in recent half century are well documented in previous studies (WD 2006; Zhou et al. 2008a), we pay more attention to the changes of precipitation over the first half century in this study. The above analysis shows that global mean precipitation derived from four datasets undergone the wettest period during 1950-1960 and the spatial distributions of precipitation anomalies of four datasets share common features. Thus it is reasonable to separate the whole twentieth century into two parts at the year 1955, which is around the peak point of global mean precipitation variation. Then the whole twentieth century is split into two parts, 1901-1955 versus 1955-2001. The linear trends of each time span and subregions are presented in Table 1. Although the trends derived from three datasets in sub-regions are different in amplitudes, the overall trends are qualitatively the same. All of them exhibit an increasing trend in global mean land precipitation during 1901-1955, and a decreasing trend during 1955-2001. The increasing trend of global mean and $\mathrm{NH}$ mean are significantly different from zero at the $95 \%$ confidence level. We have also used the year 5 years later or earlier than 1955 as a time point to separate the whole period, the overall trend signal remains the same except with different magnitudes. In addition, the selection of 1955 as a time point is also supported by the results of EOF analysis, which will be shown in the following sections.

The three datasets are consistent with each other not only in hemispheric mean, but also in latitudes bands mean. The correlation coefficients among GPCC, CRU, GHCN and Dai-dataset are all above 0.45 , which are statistically significant at the 5\% level. The above analysis demonstrates that the GPCC, CRU, GHCN and Dai-dataset bear close similarities in measuring the long-term change of precipitation. These consistencies add fidelity to our further analysis on global monsoon precipitation change during the whole twentieth century based on these datasets.

\subsection{Monsoon domain}

The patterns of long-term annual precipitation and climatological mean for the annual ranges of precipitation (AR) derived from GPCC and CRU are shown in Fig. 4. The main features of Fig. 4a, b resemble each other, including the maximum precipitation belt and the monsoon domain. The result is consistent with WD (2006), with more precipitation residing on each side of the equator, the maximum monsoon precipitation locating at extra-equatorial area, and the major 


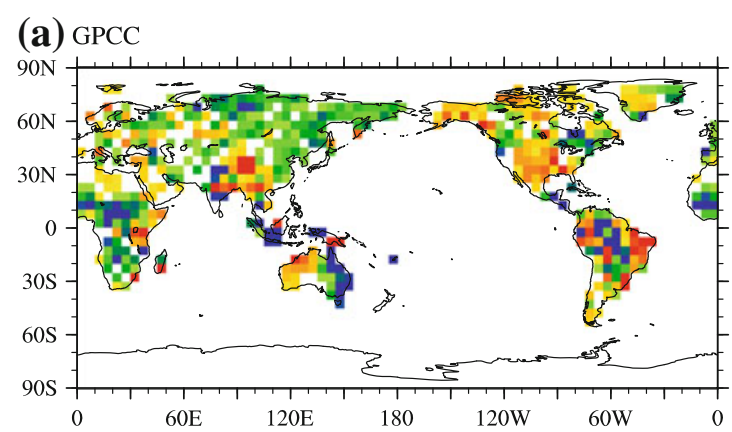

(c) GHCN

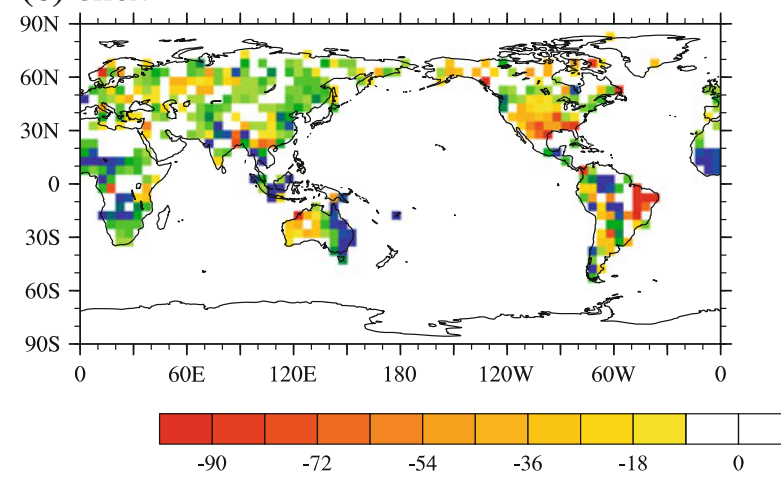

(b) $\mathrm{CRU}$

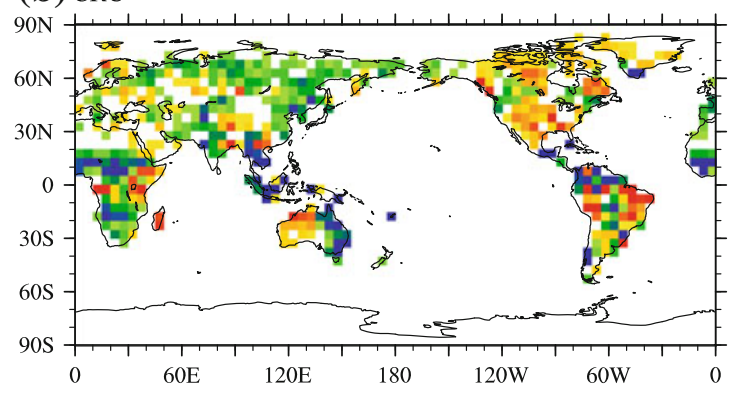

(d) Dai-dataset

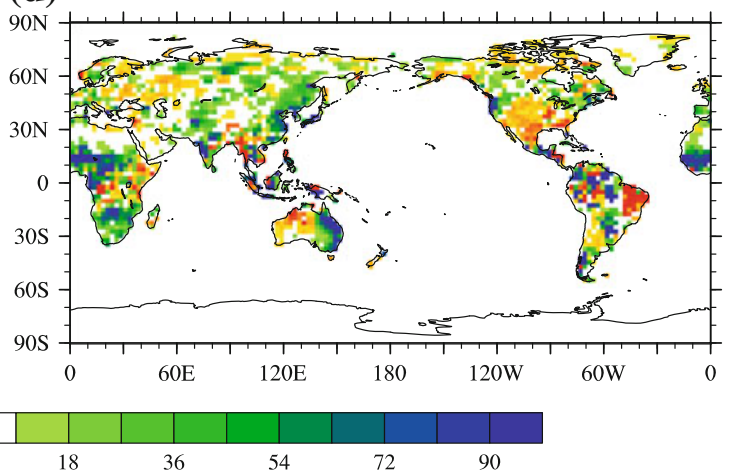

Fig. 3 The spatial distribution of annual precipitation anomaly (unit: mm) during 1950-1960 relative to 1901-2001 (1901-1995 for Dai-dataset) derived from different datasets, a GPCC, b CRU, c GHCN and d Dai-dataset

monsoon rainy regions. The pattern correlation coefficient between GPCC and CRU is 0.97 (0.98) for annual precipitation (AR), which are statistically significant at the $1 \%$ level. The largest discrepancy between the two datasets is seen over Central America, where the precipitation derived from GPCC is heavier than CRU.

In addition to global and hemispheric mean conditions, we have also examined the spatial patterns of point-bypoint correlation coefficients between two datasets (Figures not shown). Both the monthly and annual precipitation derived from GPCC dataset show significant high correlations with CRU. The correlation coefficients over most domains are above 0.7 . The lowest correlation is located in Sahara and Tibetan Plateau, which maybe due to the sparse station coverage over there. Fortunately, the correlations in our research target domain, i.e., the global monsoon regions, are high and statistically significant, which demonstrates the reliability of our forthcoming analysis.

\section{Changes of global land monsoon precipitation}

\subsection{Seasonality of global land monsoon precipitation changes}

Because of the low resolution of GHCN, only GPCC and $\mathrm{CRU}$ are used in the subsequent analysis of global monsoon precipitation. Precipitation variations derived from Dai-dataset is also shown as a reference. Based on the monsoon domain, the normalized time series of global land monsoon precipitation anomalies for annual, JJA and DJF are shown in Fig. 5. The standard deviation of three datasets ensemble mean is $34.9,15.4$ and $12.4 \mathrm{~mm}$ for the annual, JJA and DJF, respectively. The results derived from CRU, GPCC and Dai-dataset are comparable, having a correlation coefficient above 0.82. As shown in Fig. 5a, the above-normal anomalies during the period of 1950-1960 are also robust from the perspective of the twentieth century as shown in Fig. 1a, and it is reasonable to choose the year of 1955 as a time point to separate the whole twentieth century into two parts. Both the time series of annual and JJA precipitation increased slightly from 1900 to the late 1950s, and then generally decreased since the late 1950s (Fig. 5a, b). The linear trends of annual (JJA) land monsoon precipitation anomalies derived from the time series before normalization over 1901-1955 are 5.57 (1.86) $\mathrm{mm} \mathrm{decade}{ }^{-1}, 5.79$ (3.33) $\mathrm{mm} \mathrm{decade}{ }^{-1}$, and 6.93 (2.32) $\mathrm{mm} \mathrm{decade} \mathrm{d}^{-1}$ in GPCC, CRU, and Dai-dataset, respectively. The robust decreasing trend after 1955 is evident in both the annual and JJA monsoon precipitation. The corresponding linear trends of the original indices before normalization are $-8.73(-4.10) \mathrm{mm}$ decade $^{-1}$, $-6.71(-4.19) \mathrm{mm} \mathrm{decade}{ }^{-1}$, and $-20.3(-10.76) \mathrm{mm}$ decade $^{-1}$ for annual (JJA) precipitation in GPCC, CRU, 
(a) Annual mean (GPCC)

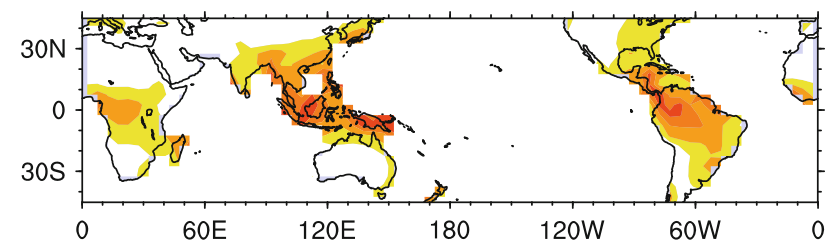

(b) Annual mean (CRU)

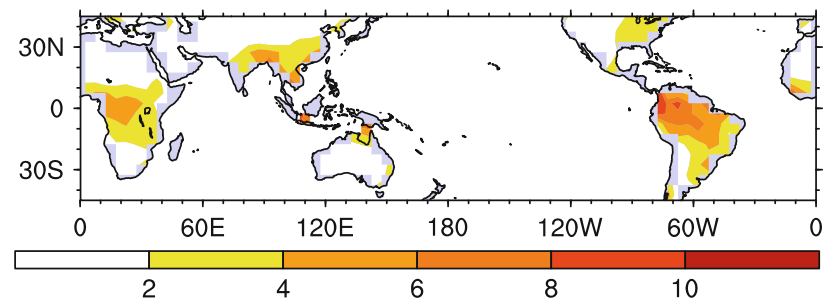

(c) Annual range(GPCC)

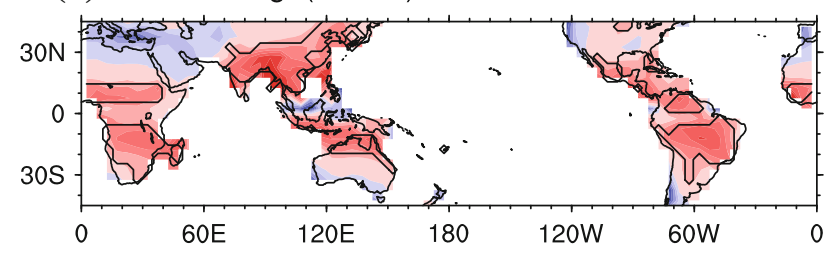

(d) Annual range( $\mathrm{CRU})$

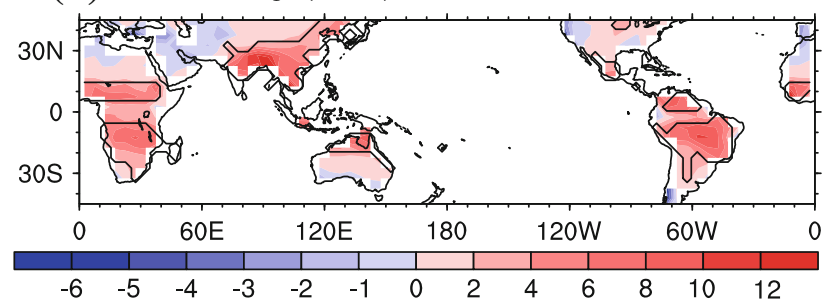

Fig. 4 The long-term annual precipitation (unit: $\mathrm{mm} / \mathrm{day}$ ) and climatologically mean for the annual range of precipitation (unit: $\mathrm{mm} /$ day), a, $\mathbf{b}$ are the annual precipitation of GPCC and CRU, $\mathbf{c}, \mathbf{d}$ are the annual range of GPCC and CRU, respectively. The bold lines in (c, d) delineate the global monsoon domain. The data period is 1901-2002

and Dai-dataset, respectively. The increasing trends of annual precipitation for 1901-1955 and drying trends of annual and JJA precipitation since 1955 derived from all datasets are statistically significant at $5 \%$ level by using 3 significance test methods. Note that the end year of Daidataset is 1995, which is in the below-normal phase of the 100 years. Therefore, the decreasing trend since 1955 derived from the Dai-dataset is much stronger than that from GPCC and CRU. No trend is evident during the period of 1901-1970 for DJF condition. The robust interdecadal variation of DJF precipitation is seen since 1960. It exhibits a below-normal condition during the 1960s, followed by above-normal condition during the 1970s, and then a decline since the 1980s. (a) Annual Mean

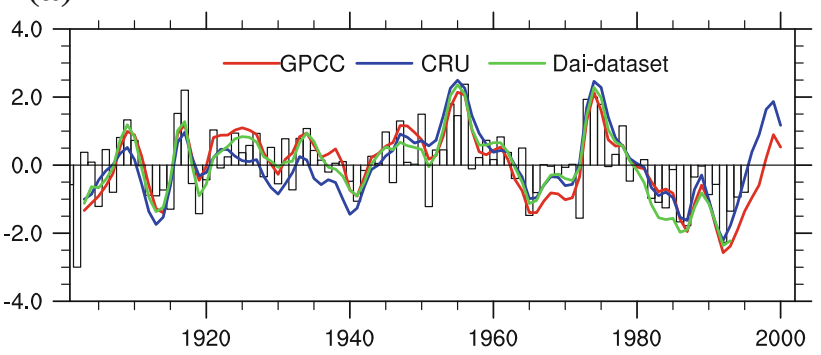

(b) JJA

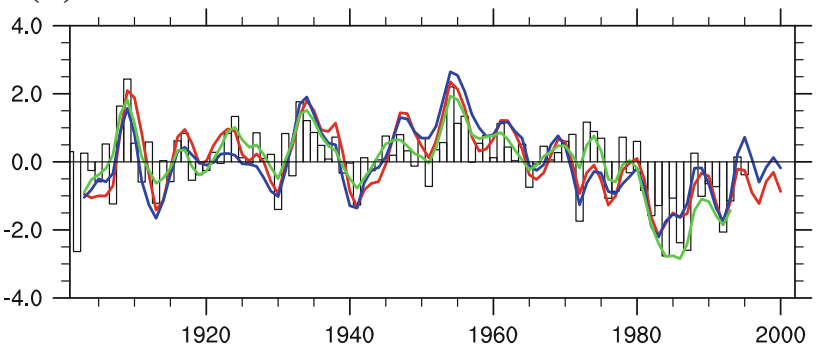

(c) DJF

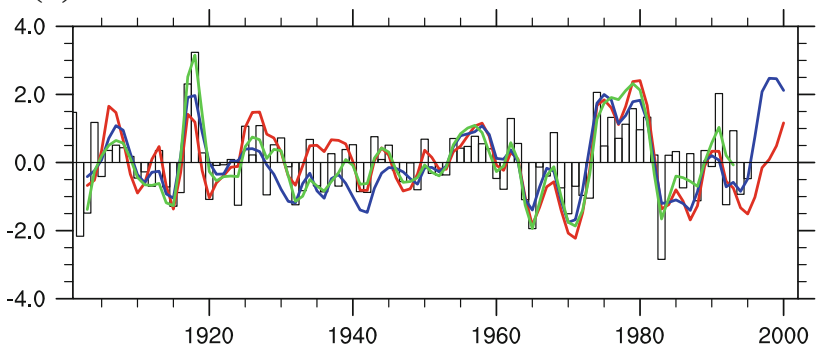

Fig. 5 Normalized time series of the global land monsoon precipitation anomalies: a annual, $\mathbf{b}$ in JJA, $\mathbf{c}$ in DJF. The bars are indices in every year based on Dai-dataset. The anomalies are calculated relative to the climate mean of 1951-1979. The red, blue and green lines are 5-year filtered indices based on GPCC, CRU and Daidataset, respectively

\subsection{Changes of global land monsoon precipitation intensity}

The normalized time series of the $\mathrm{NH}, \mathrm{SH}$, and global land monsoon precipitation strength (NHMI, SHMI and GMI) in the local summer are shown in Fig. 6. The standard deviation of ensemble mean is $25.4,28.0$ and $33.6 \mathrm{~mm}$ for the NHMI, SHMI and GMI, respectively. The results derived from the three datasets are comparable with each other. Overall, the time series indicate a decreasing trend in the NHMI and GMI (Fig. 6a, c) across the entire 100 years, and particularly after 1950 , which has been revealed in WD (2006). Of particular interest is the peak around the 1950s and the increasing trend from 1901 to 1950s in the NHMI and GMI (Fig. 6a, c). Significant tests employing T-N, MK and MC methods all show that the decreasing trends of the NHMI over the twentieth century derived from GPCC and Dai-dataset are statistically significant at the 5\% level 
(a) NHMI

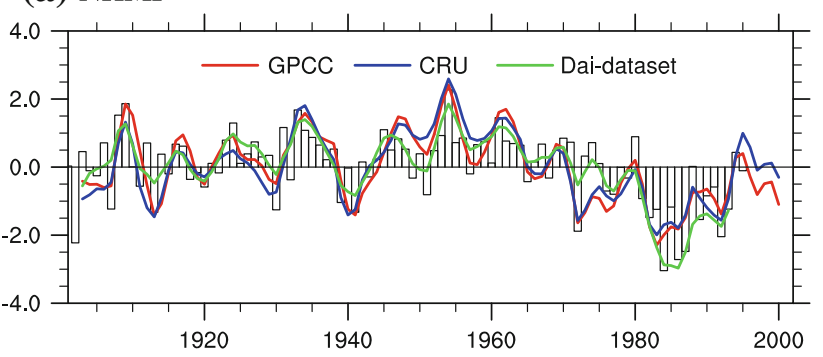

(b) SHMI

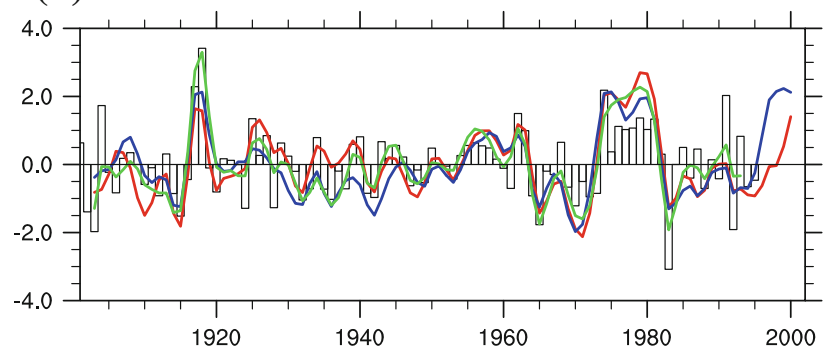

(c) GMI

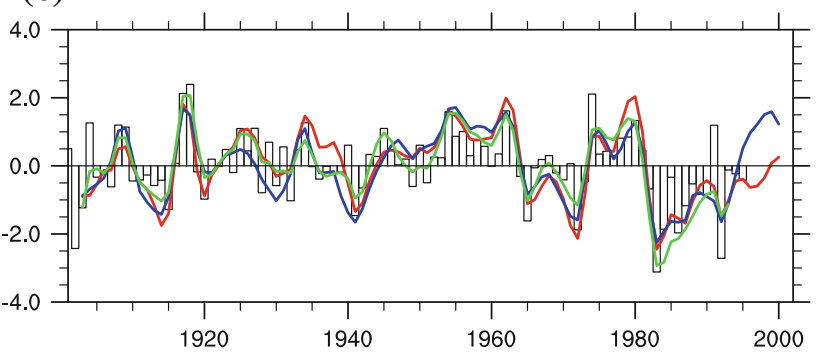

Fig. 6 Normalized time series of a NHMI, b SHMI, c GMI. The bars are indices in every year based on Dai-dataset. The red, blue and green lines are 5-year filtered indices based on GPCC, CRU and Daidataset

(See Table 2). The NHMI derived from GPCC, CRU and Dai-dataset all exhibits an increasing trend during the first half century. The increasing trends in three datasets are all significantly different from zero at the $95 \%$ confidence level by using three significance test methods. No significant trend is seen in the SHMI during either 1901-2001 or 1901-1955 (Fig. 6b). The maxima around the 1920s and the 1970s stand out in SHMI and GMI (Fig. 6b, c). Although GPCC and CRU datasets show large discrepancy in SHMI during the period of 1920-1940, the major trend features derived from three individual datasets are highly consistent, confirming the results shown in the above section.

The linear trend for all epochs and datasets and their significance tests are shown in Table 2. For the first half century, the linear trends (See Table 2) of the original GMI, NHMI and SHMI before normalization derived from Dai-dataset (GPCC, CRU) are $1.47(1.14,1.28) \mathrm{mm} \mathrm{decade}^{-1}, 1.16(1.19$, 2.30) $\mathrm{mm} \mathrm{decade}^{-1}$ and $0.31(-0.05,-1.01) \mathrm{mm} \mathrm{decade}^{-1}$, respectively. The trend of SHMI is insignificant. For the period of 1955-2001 (1955-1995 for Dai-dataset), a significant decreasing trend is seen in NHMI and GMI derived from all datasets, which is consistent with WD (2006).

\subsection{Temporal and spatial structures of global land monsoon precipitation change}

In order to reveal the coherent pattern of the changes of global monsoon precipitation intensity, we perform EOF analysis on the AR of global land monsoon domain. The EOF analysis is based on correlation matrix to stress the co-variability. The EOF1 pattern accounts for 5.2\%, $6.1 \%$ and $7.2 \%$ of the total variance in GPCC, CRU and Daidataset, respectively. However, the principal components of the second leading mode of GPCC are highly correlated with PC1 of CRU and Dai-dataset, indicating that EOF2 of GPCC is corresponding to EOF1 of CRU and Dai-dataset. The EOF2 pattern accounts for $4.7 \%$ of the total variance in GPCC. The EOF1 of CRU and Dai-dataset and EOF2 of GPCC are shown in Fig. 7a-c. The leading modes derived from the three dataset show similarities in most monsoon domains, such as the positive anomalies in northern Africa, South Asia, Northeast China, southern part of South Africa, Australia and western America, and negative anomalies in equatorial South Africa and eastern America. The largest discrepancy is seen over the southern part of Tibetan Plateau $\left(20^{\circ}-30^{\circ} \mathrm{N}, 90^{\circ}-100^{\circ} \mathrm{E}\right)$. It is negative in GPCC, while positive in CRU and Dai-dataset. It may be due to the sparse data coverage over the Tibetan Plateau. The artificial precipitation anomalies over the Tibetan Plateau derived from the GPCC is also seen in Fig. 3a.

The time evolutions of principal components derived from the three datasets show consistent variations (Fig. 7d). The correlation coefficients are 0.52 between GPCC and CRU, 0.46 between GPCC and Dai-dataset, and 0.88 between CRU and Dai-dataset. No significant linear trends are seen over the whole twentieth century. However, the change of global land monsoon precipitation is not linear for the whole 100 years. The PCs of three datasets all show an increasing tendency from 1901 to 1955 , followed by a decreasing trend from 1950s, and then a recovery since 1980s. The decreasing trend since $1950 \mathrm{~s}$ is the same as previously reported in WD (2006). The increasing trend for 1901-1955 and decreasing trend since 1950s derived from GPCC, CRU and Dai-dataset are all significant at 5\% levels (Table 2). The peak around 1950 in PC time series is evident in all the three datasets, which makes the decreasing trend being robust since 1950s. The majority of land monsoon regions gradually becomes wetter in the first half century and reaches the maximum around the 1950s. After the 1950s, a weakening tendency is seen. The overall changes of precipitation in the three datasets are highly consistent with each other. Therefore, the precipitation derived from ensemble mean of GPCC and CRU is used in the following significant test. 


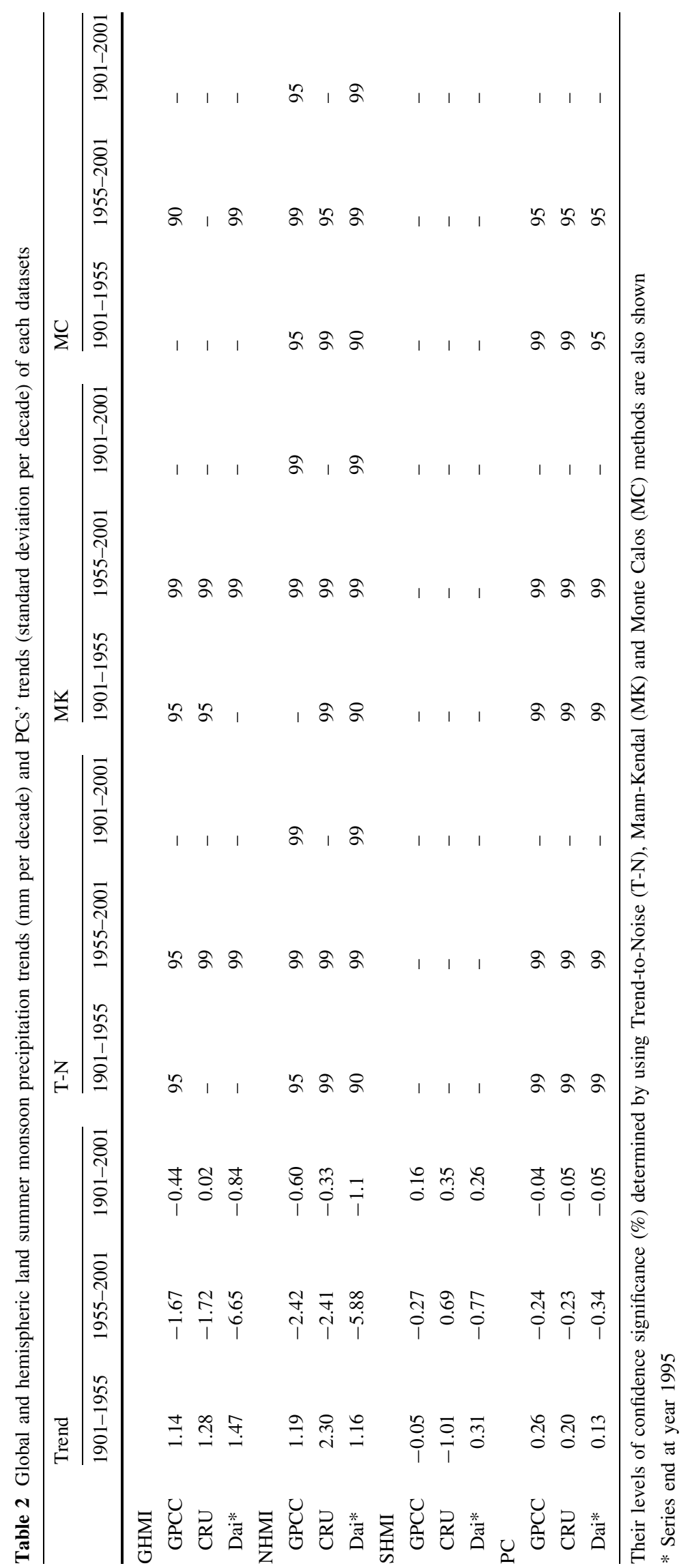


Fig. 7 The spatial pattern of the first leading EOF mode of the normalized annual range over the continental monsoon regions, a GPCC, b CRU, c Daidataset, $\mathbf{d}$ the corresponding principle component of AR. The bars in (d) are indices in every year based on Dai-dataset. The red, blue, and green lines in (d) are 5-year filtered indices based on GPCC, CRU and Daidataset, respectively. The bold contours in (a-c) indicate the boundaries of the monsoon domain (a) GPCC

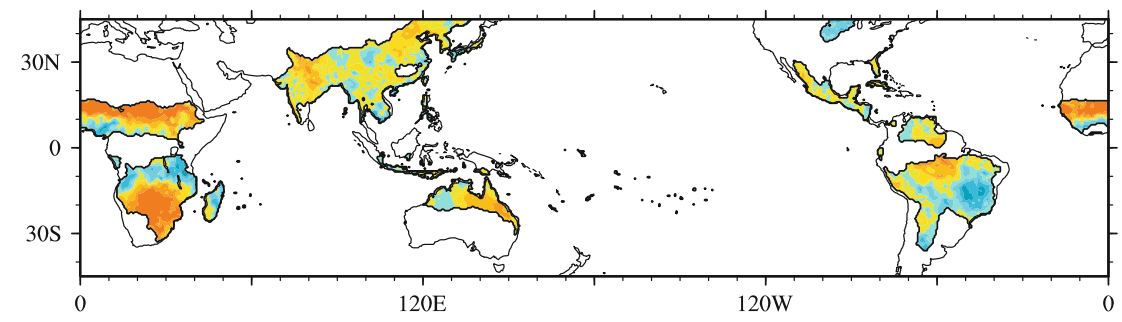

(b) $\mathrm{CRU}$

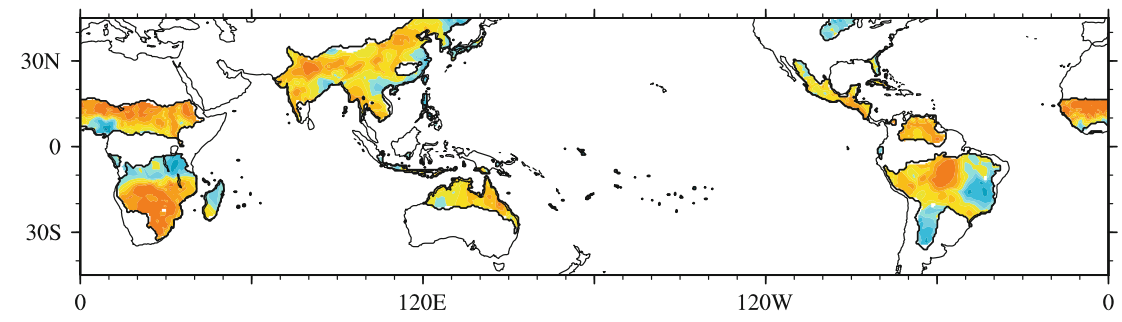

(c) Da1-dataset

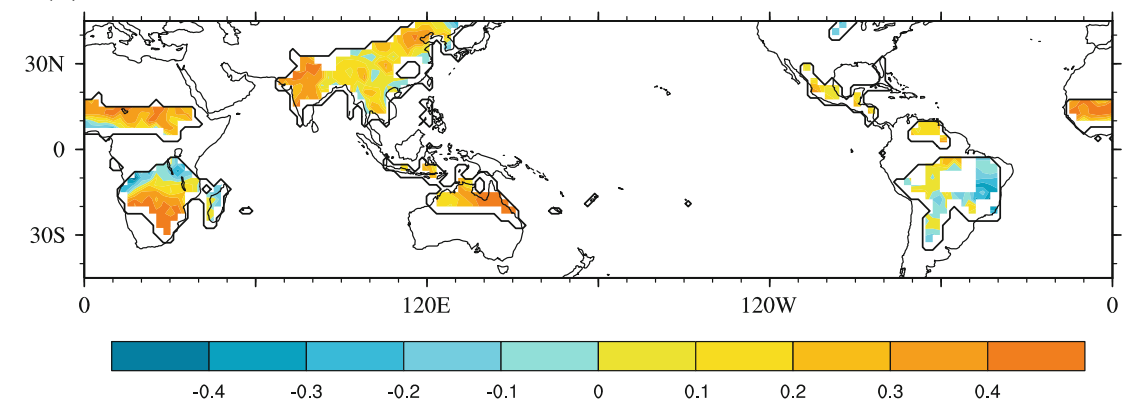

(d) PC

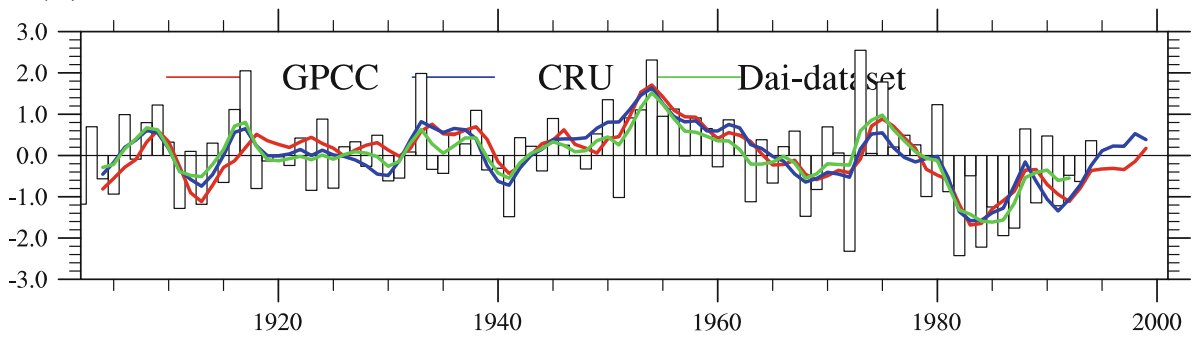

The statistical significance of the AR trend at each grid point within the land monsoon domain is shown in Fig. 8. The AR is derived from ensemble mean of GPCC and CRU. Two methods were used to test the significance of linear trends: the MK rank statistics, shown in Fig. 8a-c, and T-N test, illustrated in Fig. 8d-f. The significant spatial patterns detected by the two methods are consistent; the results also corroborate that based on EOF analysis. A strong increasing trend during 1901-1955 (Fig. 8a, d) is seen in northern Africa, southern Asia, South China $\left(10^{\circ} \mathrm{N}-20^{\circ} \mathrm{N}, 100^{\circ} \mathrm{E}-\right.$ $\left.120^{\circ} \mathrm{E}\right)$ and Northeast China $\left(30^{\circ} \mathrm{N}-45^{\circ} \mathrm{N}, 110^{\circ} \mathrm{E}-120^{\circ} \mathrm{E}\right)$, South Africa and central South America, while a decreasing trend is evident in northwestern Australia and eastern part of South America. For the period of 1955-2001 (Fig. 8c, e), the most significant drying trend is seen over the North African, Indian and central South American monsoon regions; an increasing trend is observed over Australian monsoon area. For the period of 1901-2001 (Fig. 8c, f), the monsoon rainfall intensity decreased significantly over North Africa and eastern India, but increased significantly in western Indian, Central American and Australian monsoon domains.

\subsection{Changes of precipitation in different monsoon regions}

To reveal which regional monsoon subsystems contribute to the long-term change of global land monsoon precipitation, the global monsoon domain is divided into six 
(a)Mann-Kandel

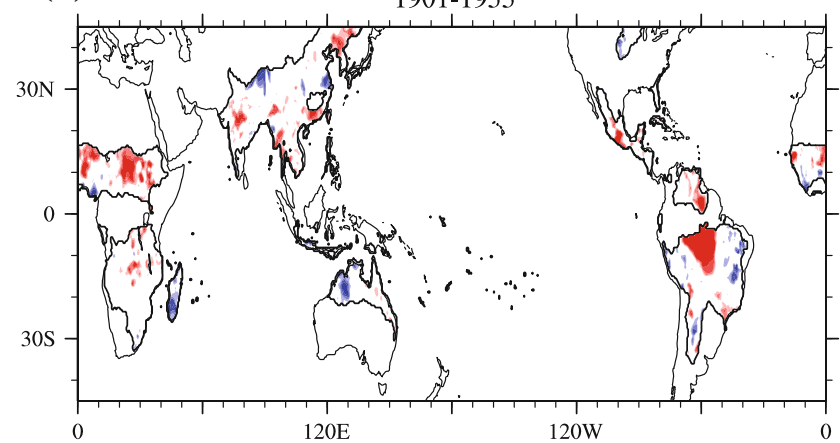

(b)Mann-Kandel

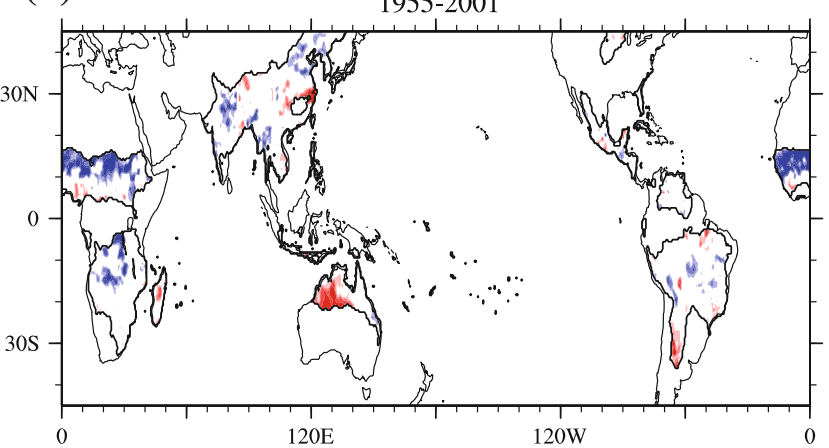

(c) Mann-Kandel

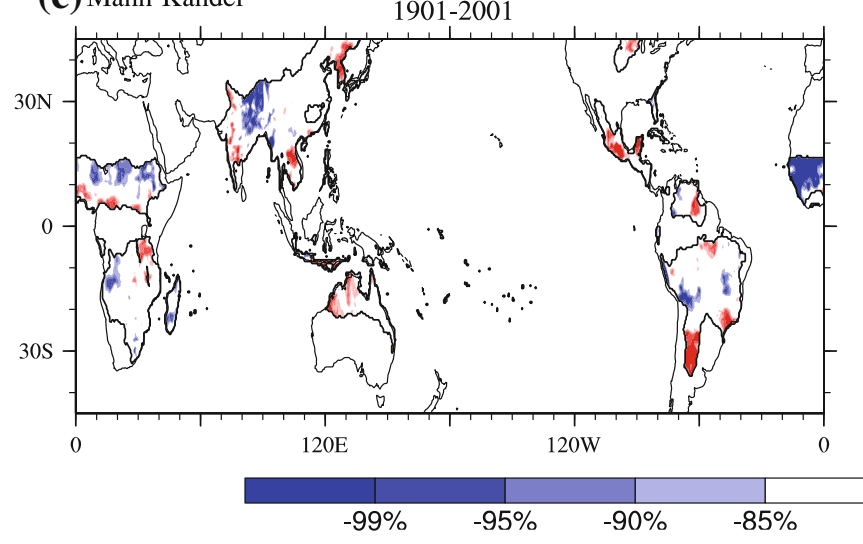

Fig. 8 Statistical significance of the linear trends in precipitation annual range at each grid point for different epochs. a-c MannKendall rank statistics test, d-f Trend-to-noise ratio test. The upper,

portions as Zhou et al. (2008a), i.e., North African monsoon, South African monsoon, South Asian monsoon, East Asian monsoon, Australian monsoon, and South American monsoon domains. The time series of monsoon precipitation strength for each individual monsoon subsystems are shown in Fig. 9. For the period of 1901-1955, an apparent upward trend is seen in the North African monsoon and East Asian monsoon. The increasing trend of East Asian monsoon precipitation is due to the excessive precipitation over South China and Northeast China (Fig. 8a, d). Based on the 71 stations over China where data are available for (d) Trend to Noise test

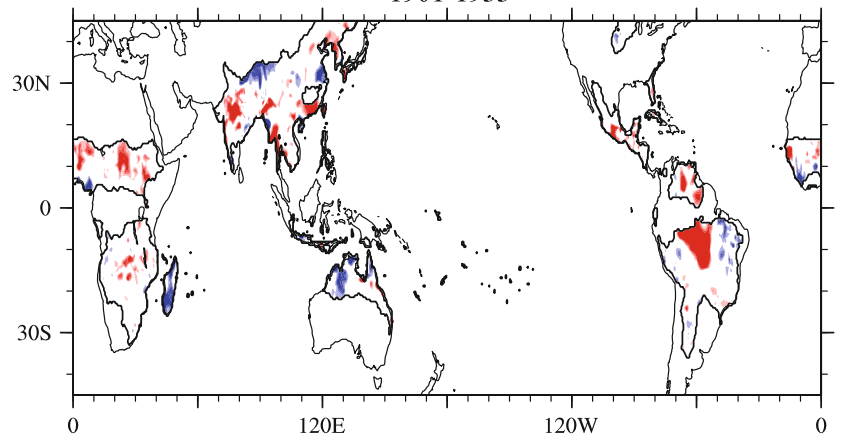

(e) Trend to Noise test 1955-2001

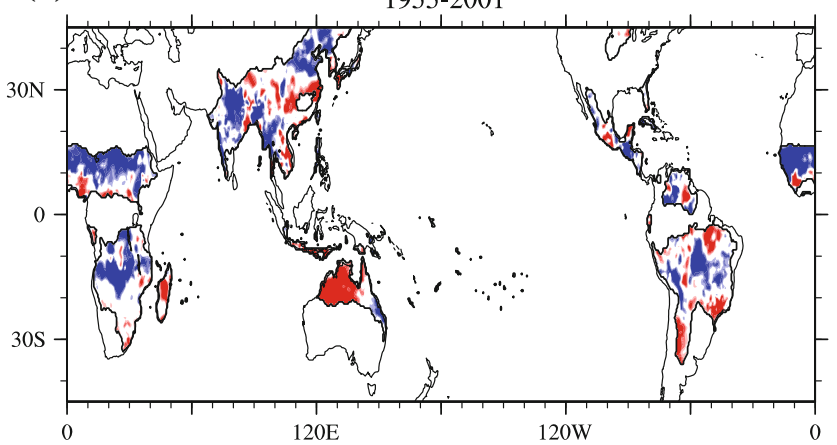

(f) Trend to Noise test 1901-2001

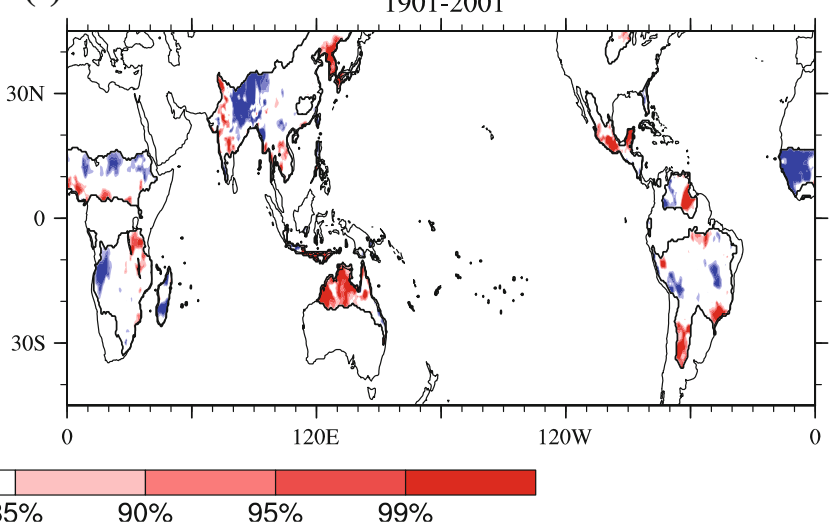

middle and bottom panels are for 1901-1955, 1955-2001 and 1901-2001, respectively. The precipitation annual range is derived from ensemble mean of CRU and GPCC

1880-2002, Wang and Li (2007) showed the area-averaged mean summer precipitation over Yangtze River Valley $\left(25^{\circ} \mathrm{N}-35^{\circ} \mathrm{N}\right.$, east of $\left.100^{\circ} \mathrm{E}\right)$ and northern China $\left(35^{\circ} \mathrm{N}-\right.$ $45^{\circ} \mathrm{N}$, east of $100^{\circ} \mathrm{E}$ ) decreased and increased for 1900-1950, respectively. Our results are consistent with their results. A downward trend is seen over the South African and Australian monsoon since 1920-1950. The South Asian monsoon shows stronger than normal monsoon during the period of 1915-1925 and 1930-1945, which is identical to the reconstructed dynamic Indian monsoon index and all Indian monsoon rainfall index 


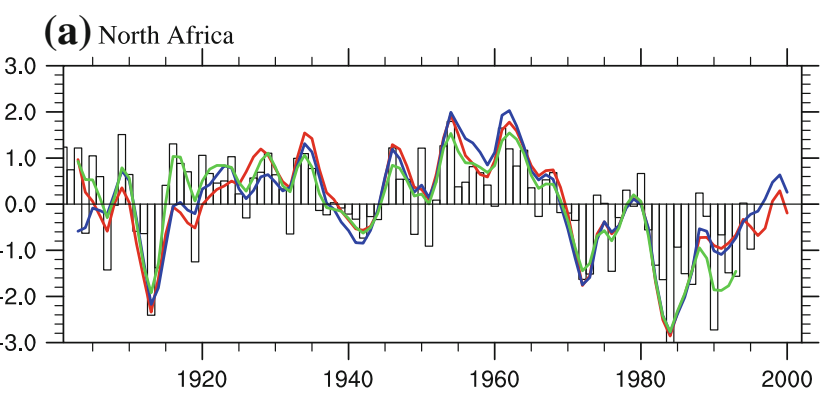

(c) Indian

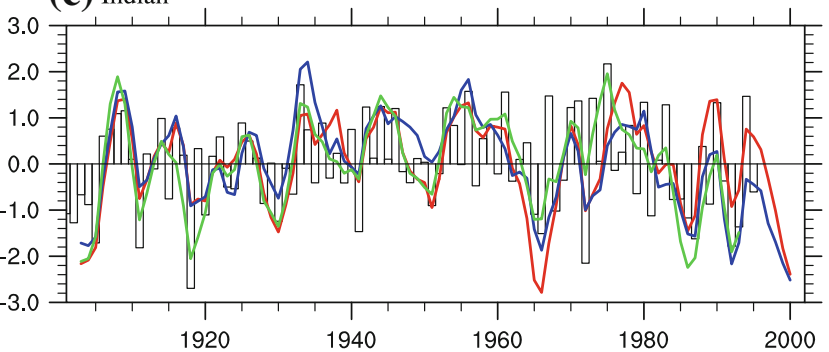

(e) Australia

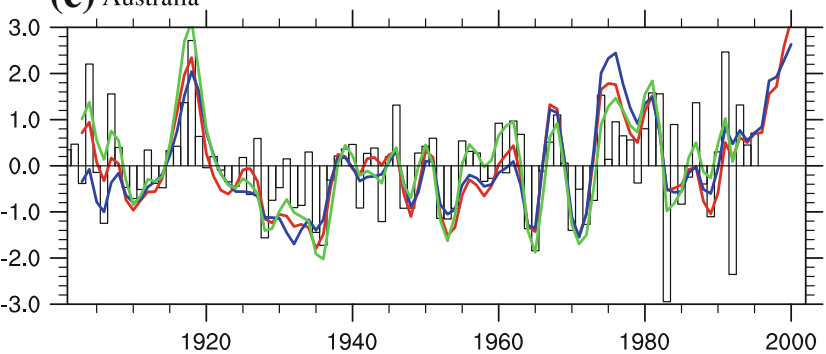

Fig. 9 Normalized time series of local summer (JJA in NH, DJF in $\mathrm{SH})$ precipitation anomalies for different regional monsoon domains. a North African monsoon; b South African monsoon; c South Asian monsoon; d East Asian monsoon; e Australian monsoon; f South

(Zhou et al. 2009b). A wetter period around 1950 stands out over the North African, South African, Indian and East Asian monsoon.

The trends across 1901-1955, 1955-2001 and 19012002 for all sub-regions derived from GPCC, CRU and Dai-dataset are given in Table 3. Consistent trends are seen not only for 1901-1955, but also for the whole twentieth century. All regional monsoon systems in northern hemisphere exhibit an upward trend during 1901-1955. However, only the trend of East Asian monsoon is statistically significant at $5 \%$ level though by using three statistic test methods. The decreasing trends of African and Indian monsoon are significantly different from zero at the $90 \%$ confidence level by using T-N and MC test. A discrepancy among GPCC, CRU and Dai-dataset is seen over the South African and South American monsoon domain, where the linear trends are not statistically significant. A downward trend is seen in Australian monsoon, which is statistically significant at $10 \%$ level. Therefore, the increasing tendency (b) South Africa

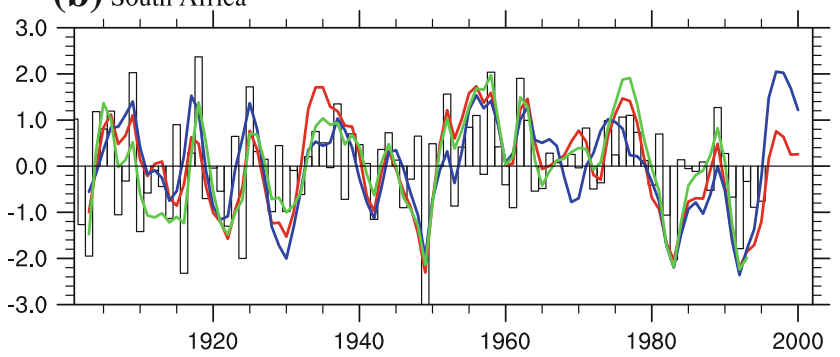

(d) East Asia

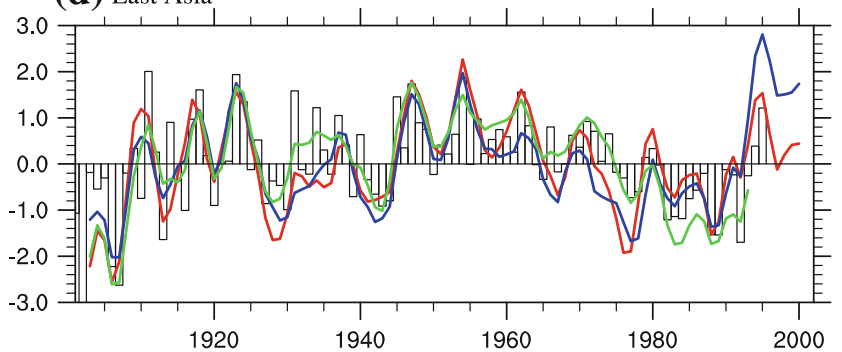

(f) South America

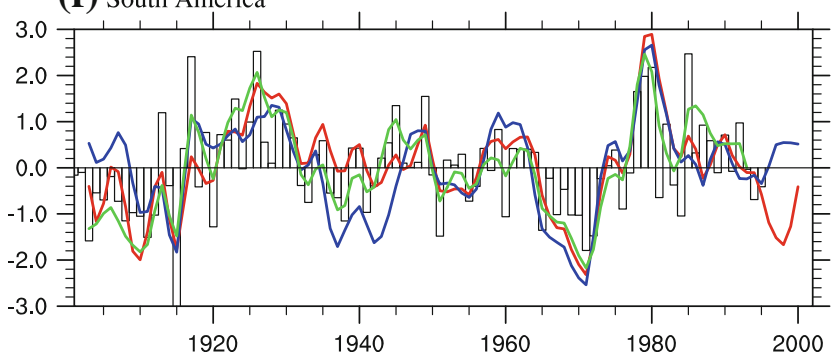

American monsoon. The bars are indices in every year based on Daidataset. The anomalies are calculated relative to the climate mean of 1951-1979. The red, blue, and green lines are 5-year filtered indices based on GPCC, CRU and Dai-dataset, respectively

of NH land monsoon precipitation for the first half century mainly comes from the North African, Indian and East Asian monsoon. For the period of 1955-2001, the decreasing trends over North African monsoon are statistically significant at $5 \%$ level by using three significance test methods. The declined trend of Indian monsoon rainfall derived from CRU and Dai-dataset are also significant. The above decreasing trends of North African and Indian monsoon are consistent with Zhou et al. (2008a). The Australian monsoon rainfall increased significantly for all datasets during 1955-2001. For the whole twentieth century, only the precipitation over North African monsoon has experienced a significant decreasing trend and only the Australian monsoon has experienced a robust upward trend. The long-term trends of South Africa, East Asian, North American and South American monsoon precipitation are statistically insignificant.

Hence the weakening tendency of $\mathrm{NH}$ land monsoon precipitation over the past 100 years is mainly caused by 


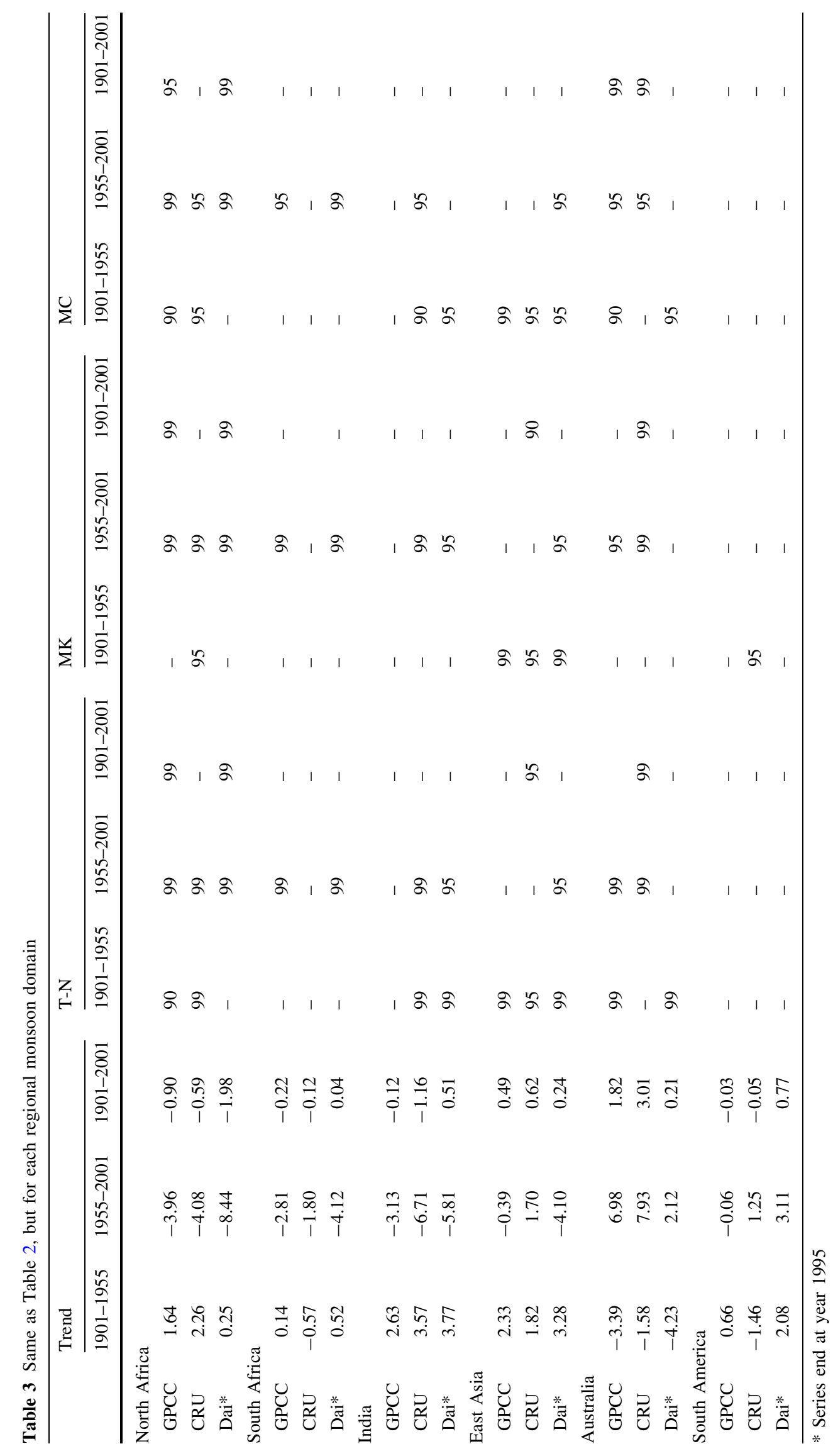


the North African monsoon precipitation. The drought over North Africa in the latter half of the twentieth century has been well documented (Zeng et al. 1999; Nicholson et al. 2000; Dai et al. 2004; Hoerling et al. 2006; Scaife et al. 2009). By using two different station precipitation datasets (GHCN database is included), Dai et al. (2004) concluded that the deceasing trend in Sahel is not an artifact of changing station networks. The SH land monsoon precipitation shows a weak increasing trend, which is resulted from the Australian monsoon.

\subsection{The impact of station-coverage on monsoon precipitation changes}

The change of station and inclusion of new station data may affect the derived interdecadal variation and long-term trend of precipitation. To estimate the magnitude of the station-coverage-induced bias on land monsoon precipitation changes, we extract the stations with available observational JJA rainfall data since 1900, 1905 and 1910 from the updated GHCN2 dataset, respectively. The NHMI and regional summer (JJA) monsoon precipitation in northern hemisphere were recalculated by using the selected station data. The selected stations have continuous or nearly continuous (i.e., the total years without observational JJA rainfall data are less than 30 years) JJA rainfall data since 1900, 1905 and 1910, respectively. Following Dai et al. (1997), the station data was re-gridded onto a $2.5^{\circ} \times 2.5^{\circ}$ grid by using the inverse distance-weighted scheme. The selected datasets are called sampled datasets in the following discussion. The sampled datasets with stations since 1900, 1905 and 1910 are named 1900-sampled, 1905-sampled and 1910-sampled dataset, respectively. Note in the individual dataset such as 1900-sampled dataset, the station number used in the analysis does not change with time. Thus by comparing the results derived from three individual dataset, the influence of station number change can be assessed. The analysis presented above indicates that only the NHMI has a decreasing trend during 1900-2001. So only the NHMI and northern hemispheric regional monsoon precipitation are re-examined in the following analysis.

The distributions of selected stations of the sampled datasets over North African, Indian and East Asian monsoon region are shown in Fig. 10a-c. For the 1900-sampled dataset, there are 17, 42, 35 stations having continuous or nearly continuous JJA rainfall data in North African, Indian and East Asian monsoon region, respectively (Fig. 10a). The station-coverage has increased from 1900 to 1910 , especially over the North African monsoon domain. The corresponding station number of 1905-sampled (1910sampled) dataset has increased to 41 (73), 43 (44) and 54 (67), respectively. In the 1900-sampled dataset, the 17 stations in North African monsoon domain are mainly located in western Africa, and only two stations are located in eastern part. Thus the spatial coverage of 1900-sampled dataset can not represent the whole North African monsoon domain. With the increase of stations, the North African monsoon domain is well covered in both 1905-sampled and 1910-sampled datasets. In the Indian monsoon domain, the station coverage is intense and enough to represent the Indian monsoon in all three sampled datasets. In East Asian monsoon, the coverage of stations is better than that of North African monsoon, and comparable to that of Indian monsoon. The change of station-coverage in Indian and East Asian monsoon is not significant in three sampled datasets.

To examine the magnitude of station-coverage-induced bias on the monsoon precipitation changes, the JJA precipitation anomalies of Northern Hemispheric land monsoon and regional monsoon domains in $\mathrm{NH}$ are shown in Fig. 11. The anomalies are relative to the climate mean of 1910-1995, which is the common period of three sampled datasets and Dai-dataset. It is evident that the index derived from lower station coverage tends to have larger amplitude. The largest discrepancy is seen over the North African monsoon region as expected. This is caused by the sparse station coverage in North African monsoon region in 1900-sampled dataset (Fig. 10a). Thus the North African monsoon precipitation change derived from the 1900-sampled dataset exhibits a large bias and will not be included in the following discussion. The indices derived from the left two sampled datasets are comparable to that of Dai-dataset in North African monsoon domain, indicating an increase of station number from 41 to 73 over North Africa does not have significant influence on the results. In Indian and East Asian monsoon area, the results derived from three sampled datasets are comparable due to the relatively intense stations, especially after 1905 . The major features of NHMI, Indian monsoon and East Asian monsoon land precipitation changes can be seen in all the sampled datasets. The overall increasing trends of NHMI, Indian monsoon and East Asian monsoon domains for 1901-1955 are also evident in the 1905-sampled and 1910-sampled dataset, and both Indian and East Asian monsoon JJA precipitation exceed 5\% significant level by using T-N and MC test methods. For 1955-2000, declined precipitation intensity trends of NHMI and North African monsoon rainfall intensity are evident in all sampled datasets, and the North African monsoon rainfall are significant at $5 \%$ level in all sampled datasets. The results are consistent with that of Wang and Ding (2006), which is based on intense modern rain gauge observation network. The NHMI derived from 1910-sampled dataset are significant at $5 \%$ level by using 3 significance test methods. 
(a) 1900-sampled dataset

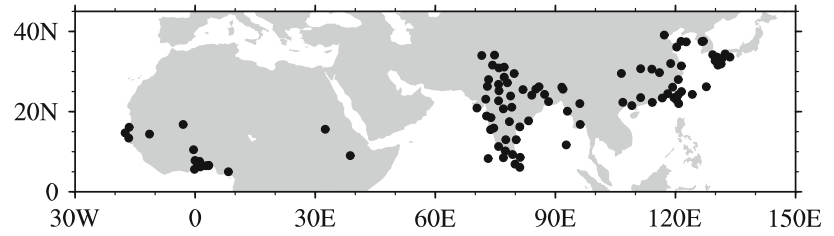

(b) 1905 sampled dataset

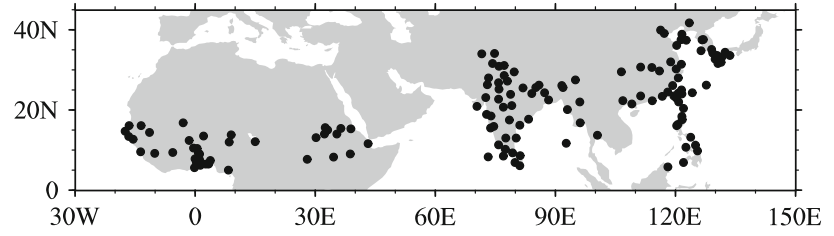

(c) 1910-sampled dataset

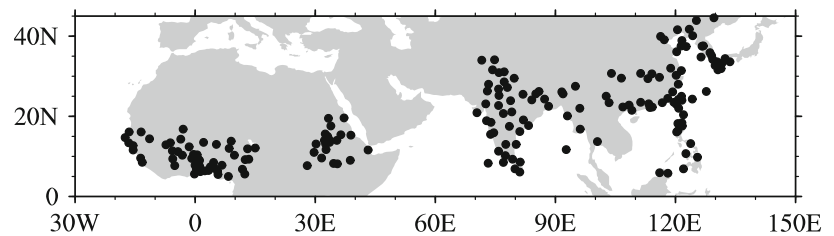

Fig. 10 Distribution of rain-gauge stations (big dots) with continuous or nearly continuous data in a 1900-sampled data, b 1905-sampled data, c 1910-sampled data

(a) NHMI

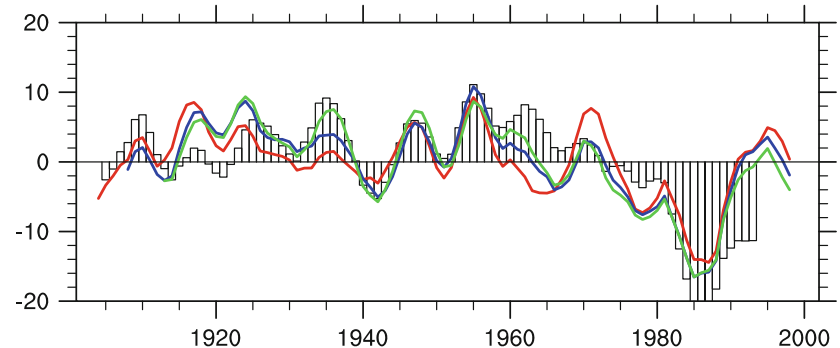

(c) India

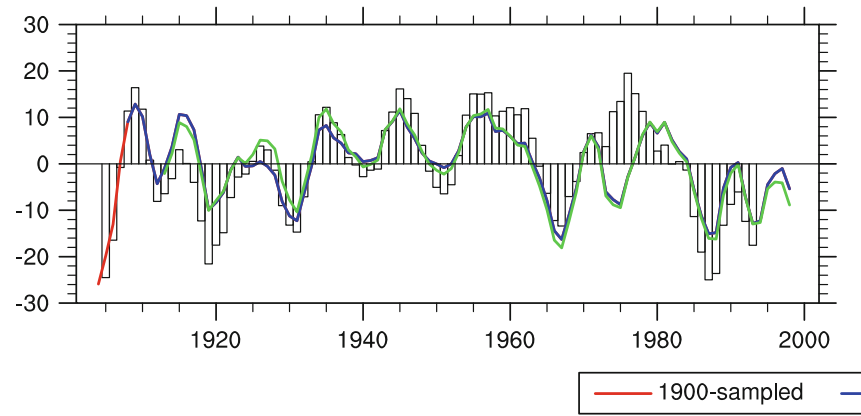

Fig. 11 Time series of JJA precipitation anomalies (unit: $\mathrm{mm}$ ) for $\mathrm{NH}$ land monsoon mean and regional monsoon domains in $\mathrm{NH}$. a NHMI, b North African monsoon; c Indian monsoon; d East Asian monsoon. The anomalies are calculated relative to the climate mean
The above analysis indicates that the impact of stationcoverage on the change of northern hemispheric land monsoon precipitation is relatively small during the twentieth century, especially after 1905 . When the station numbers are large enough to cover the primary part of monsoon domain (such as Indian monsoon and East Asian monsoon), the inclusion of new station data do not affect the trend signal, albeit with a discernible influence on the magnitude (Fig. 11c, d). Our examination on the impact of stationcoverage demonstrated that the long-term variability of monsoon precipitation shown in above sections is reliable, including the increasing tendency during 1901-1955 in Indian and East Asian monsoon precipitations, the decreasing trend of North African monsoon precipitation during 1955-2001, the upward trend during 1905-1955 and downward trend during 1955-2001 in NHMI.

\section{Summary and discussion}

\subsection{Summary}

Changes in the global land monsoon precipitation are examined by using three sets of rain-gauge precipitation

(b) North Africa

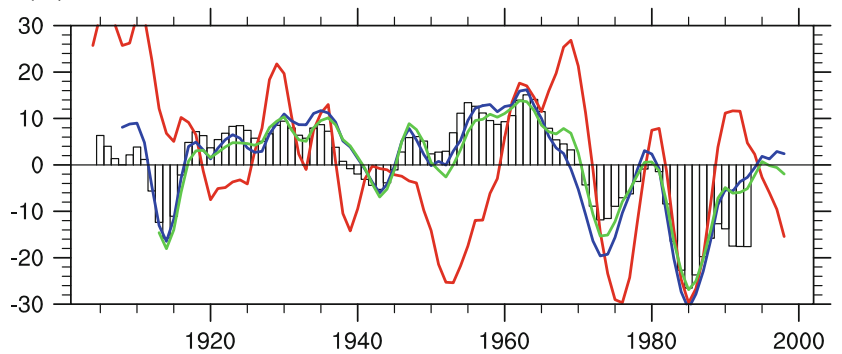

(d) East Asia

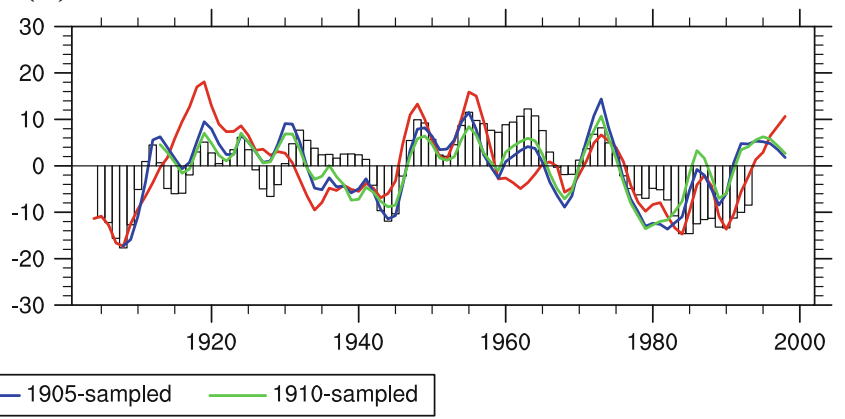

of 1910-1995. The red, blue, and green lines are 5-year filtered indices are derived from 1900-sampled, 1905-sampled, 1910-sampled dataset, respectively. The bars are 5-year filtered indices based on Dai-dataset 
data for the period of 1901-2001 compiled by GPCC, CRU and Dr. Aiguo Dai, respectively. The three datasets are highly consistent in measuring the long-term changes of seasonal precipitations, especially over the monsoon region. Multi-decadal variability of global land monsoon precipitation is revealed. The result shows that the previously reported decreasing tendency of global land monsoon precipitation over the past 56 years is only a phenomenon of recent half century, in the first half of the twentieth century the global land monsoon precipitation exhibits an increasing rather than decreasing tendency. The major findings are summarized below:

(1) Over the twentieth century, the global land monsoon precipitation (GMI) changes show an overall increasing trend from 1901 to 1955 , and then a decline trend up to the present time. Overall, only the NHMI has experienced a significant decreasing trend across the entire 100 years, but this overall trend is actually resulted from the downward trend since the 1950s. The significant decreasing trend of the NHMI mainly comes from the downward trend of the North African monsoon precipitation. No significant longterm trend is seen in the SHMI. The peak around 1950-1960 stands out in NHMI and GMI, while the maximum around the 1920s and 1970s are robust in SHMI and GMI.

(2) For the first half century, both the GMI and NHMI show increasing trends, and NHMI is statistically significant at $5 \%$ level. The obvious increasing trend of the northern hemispheric land summer monsoon precipitation during the period of 1901-1955 is mainly caused by the North African, Indian and East Asian monsoon precipitation. Besides the increasing trend, a robust downward trend is seen over the Australian monsoon regions during 1901-1955. A wetter period around 1950 stands out over North African, South African, Indian and East Asian monsoon.

(3) Based on EOF analysis, the leading mode of precipitation annual range in global land monsoon domains indicates a coherent change of North African, South Asian, Northeast China, southern South African, eastern Australian and western American monsoon, and a coherent change over the equatorial South African monsoon and eastern American monsoon. The corresponding principal component time series suggest that most land monsoon precipitation has experienced an increasing tendency from 1901 to 1955 and a decreasing trend since 1950s.

(4) Examination on the impact of station-coverage on monsoon precipitation changes reveals a relatively small influence of station-coverage, especially after 1905. Before 1905, the sparse station coverage in North African monsoon domain is not enough to accurately describe the North African monsoon. In Indian and East Asian monsoon area, the inclusion of new station dose not affect the major features of monsoon variability. Thus the increasing tendency of the Indian and East Asian monsoon precipitations during the period of 1901-1955 is reliable. The upward trend during 1905-1955 and downward trend during 1955-2001 NHMI are real.

\subsection{Discussion}

This study reveals a transition of global land monsoon precipitation from a strong phase to a weak phase around the 1950s in terms of interdecadal variability. The longterm precipitation trends depend heavily on the observational precipitation data. Fortunately, the three dataset employed by this study have a high consistency over the monsoon domain, which adds reliability to the results. The drought over the North Africa has been well documented by many scientists and thereby should be reliable (Zeng et al. 1999; Nicholson et al. 2000; Dai et al. 2004; Hoerling et al. 2006; Scaife et al. 2009). There are also many studies about the South Asia monsoon. Our results about Indian monsoon precipitation agree with that of Ramanathan et al. (2005), Duan and Yao (2004) and Zhou et al. (2009b). Moreover, the intense observation stations over the Indian monsoon add reliability to the downward trend over the twentieth century reported here.

The main contribution of this study is to provide a full observational picture of the long-term changes of global land monsoon precipitation across the whole twentieth century. Further studies are necessary for a clear explanation of the observed changes. The simultaneous correlation coefficient between the PC1 (Fig. 7d) and the simultaneous JJA Nino-3.4 index (defined as SST anomalies averaged within the box of $5^{\circ} \mathrm{S}-5^{\circ} \mathrm{N}, 120^{\circ} \mathrm{W}-170^{\circ} \mathrm{W}$ ) reaches -0.68 , indicating that the leading mode of the annual range of land monsoon precipitation concurs with the ENSO. This is consistent with the previous studies (Ropelewski and Halpert 1987; Dai and Wigley 2000; Zhou et al. 2008b). Whether and how does ENSO affect the long-term variability of global monsoon precipitation is not clear. The impact of external forcings on global monsoon precipitation has been discussed but is still inconclusive. Kim et al. (2008) examined the global land monsoon trend simulated by 21 coupled global climate models participated in CMIP3, and found that external volcanic forcings played an important role on the decreasing trend in the northern hemispheric land monsoon precipitation over the latter half of twentieth century.

In addition, climate models play crucial roles in understanding and simulating the past, present, and future precipitation change (Findell and Delworth 2010). Our results of the global land monsoon precipitation change during the whole twentieth century may serve as a useful observational reference for the future modeling studies of longterm drought and pluvial frequency changes. 
Acknowledgments This work was jointly supported by the China R\&D Special Fund for Public Welfare Industry (meteorology) (GYHY200706010, GYHY200806010) and the National Natural Science Foundation of China under Grant Nos. 40890054 and 90711004. We thank Ms. Wenmin Man for polishing the English grammar and her helpful suggestions.

Open Access This article is distributed under the terms of the Creative Commons Attribution Noncommercial License which permits any noncommercial use, distribution, and reproduction in any medium, provided the original author(s) and source are credited.

\section{References}

Biasutti M, Battisti D, Sarachik E (2003) The annual cycle over the tropical Atlantic, South America, and Africa. J Clim 46:2491-2508

Bradley $R$ et al (1987) Precipitation fluctuations over northern hemisphere land areas since the mid-19th century. Science 237(4811): 171

Chen M, Xie P, John E (2001) Global land precipitation: a 50-year monthly analysis based on gauge observations. J Hydrometeorol 3:249-266

Dai A, Wigley T (2000) Global patterns of ENSO-induced precipitation. Geophys Res Lett 33(9):1283-1286

Dai A, Fung I, Genio A (1997) Surface observed global land precipitation variations during 1900-1988. J Clim 10:2943-2962

Dai A, Lamb P, Trenberth K, Hulme M, Jones P, Xie P (2004) The recent Sahel drought is real. Int J Climatol 24:1323-13331

Diaz H, Bradley R, Eischeid J (1989) Precipitation fluctuations over global land areas since the late 1800's. J Geophys Res 94:1195-1210

Duan K, Yao T (2004) Low-frequency of southern Asian monsoon variability using a 295-year record from the Dasuopu ice core in the central Himalayas. Geophys Res Lett 31:L16209. doi: 10.1029/2004GL020015

Findell K, Delworth T (2010) Impact of common sea surface temperature anomalies on global drought and pluvial frequency. J Clim 23:485-503

Hoerling M, Hurrell J, Eischeid J, Phillips A (2006) Detection and attribution of twentieth-century northern and southern African rainfall change. J Clim 19:3989-4008

Hulme M (1995) Estimating global changes in precipitation. Weather Lond 50:34

Jones D, Collins D, Nicholls N, Phan J, Della-Marta P (2004) A new tool for tracking Australia's climate variability and change. Bull Aust Met Oceanogr Soc 17:65-69

Kendall M (1955) Rank correlation methods. Oxford University Press, USA, p 196

Kim H, Wang B, Ding Q (2008) Assessing the global monsoon simulated by the CMIP3 coupled climate models. J Clim 21:5271-5294

Kripalani R, Kulkarni A (2001) Monsoon rainfall variations and teleconnections over south and East Asia. Int J Climatol 21:603-616

Lau K, Weng H (2002) Recurrent teleconnection patterns linking summertime precipitation variability over East Asia and North America. J Meteorol Soc Jpn 80:1309-1324

Meehl G (1997) The south Asian monsoon and the tropospheric biennial oscillation. J Clim 10:1921-1943

Mitchell T, Jones P (2005) An improved method of constructing a database of monthly climate observations and associated highresolution grids. Int J Climatol 25:693-712
New M, Todd M, Hulme M, Jones P (2001) Precipitation measurements and trend in the twentieth century. Int $\mathrm{J}$ Climatol 21(15):1889-1922

Nicholls N, Lavery B (1992) Australian rainfall trends during the twentieth century. Int J Climatol 12(2):153-163

Nicholson S, Some B, Kone B (2000) An analysis of recent rainfall conditions in West Africa, including the rainy seasons of the 1997 El Niño and the 1998 La Niña years. J Clim 13:2628-2640

Ramanathan V et al (2005) Atmospheric brown clouds: impacts on South Asian climate and hydrological cycle. Proc Natl Acad Sci USA 102:5326-5333

Ropelewski C, Halpert M (1987) Global and regional scale precipitation patterns associated with the El Nino-Southern oscillation. Mon Weather Rev 115(8):1606-1626

Scaife A, Kucharski F, Folland C et al (2009) The CLIVAR C20C project: selected twentieth century climate events. Clim Dyn 33:603-614. doi:10.1007/s00382-008-0451-1

Schneider U, Fuchs T, Meyer-Christoffer A, Rudolf B (2008) Global Precipitation Analysis Products of the GPCC. Global Precipitation Climatology Centre (GPCC), DWD, Internet Publication, $1-12$

Schreck C, Semazzi F (2004) Variability of the recent climate of eastern Africa. Int J Climatol 24:681-701

Trenberth K, Stepaniak D, Caron J (2000) The global monsoon as seen through the divergent atmospheric circulation. J Clim 13:3969-3993

Trenberth K, Jones P, Ambenje P, Bojariu R et al (2007) Observations: Surface and Atmospheric Climate Change. In: Solomon S, Qin D, Manning M, Chen Z, Marquis M, Averyt K, Tignor M, Miller H (eds) Climate change 2007: the physical science basis. Contribution of working group I to the fourth assessment report of the intergovernmental panel on climate change. Cambridge University Press, Cambridge, pp 235-336

Vinnikov K, Groisman P, Lugina K (1990) Empirical data on contemporary global climate changes (temperature and precipitation). J Clim 3(6):662-677

Wang B, Ding Q (2006) Changes in global monsoon precipitation over the past 56 years. Geophys Res Lett 33:L06711. doi: 10.1029/2005GL025347

Wang B, Ding Q (2008) The global monsoon: major modes of annual variation in tropical precipitation and circulation. Dyn Atmospheres Oceans 44:165-183

Wang S, Li W (2007) Climate Disasters. In: Wang S, Li W (eds) Climate of China. China Meteorological Press, Beijing, pp 143-145

Wang S, Zhu J et al (2004) Interdecadal variability of temperature and precipitation in China since 1880. Adv Atmospheric Sci 21(3):307-313

Webster P, Palmer T, Yanaiet M et al (1998) Monsoons: processes, predictability and the prospects for prediction. J Geophys Res 103:14451-14510

Wilks D (1995) Statistical methods in the atmospheric sciences: an introduction. Elsevier, New York, p 467

Woodward W, Gray H (1993) Global warming and the problem of testing for trend in time series data. J Clim 6(5):953-962

Yu R, Zhou T (2007) Seasonality and three-dimensional structure of the interdecadal change in East Asian monsoon. J Clim 20:53445355

Yu R, Wang B, Zhou T (2004) Tropospheric cooling and summer monsoon weakening trend over East Asia. Geophys Res Lett 31:L22212. doi:10.1029/2004GL021270

Zeng N, Neelin J, Lau K, Tucker C (1999) Enhancement of interdecadal climate variability in the Sahel by vegetation interaction. Science 286:1537-1540

Zhang P, Yang S, Kousky V (2005) South Asian high and AsianPacific-American climate teleconnection. Adv Atmospheric Sci 22(6):915-923 
Zhang X, Zwiers F, Hegerl G, Lambert F, Gillett N, Solomon S, Stott P, Nozawa T (2007) Detection of human influence on 20th century precipitation trends. Nature 448(7152):461-465

Zhou T, Zhang L, Li H (2008a) Changes in global land monsoon area and total rainfall accumulation over the last half century. Geophys Res Lett 35:L16707. doi:10.1029/2008GL034881

Zhou T, Yu R, Li H et al (2008b) Ocean forcing to changes in global monsoon precipitation over the recent half century. J Clim 21:3833-3852
Zhou T, Gong D, Li J, Li B (2009a) Detecting and understanding the multi-decadal variability of the East Asian summer monsoon-recent progress and state of affairs. Meteorol Z 18(4):455467

Zhou T et al (2009b) A reconstructed dynamic Indian monsoon index extended back to 1880. Clim Dyn 34(4):573-585 